of the background of these differences, he emphasizes that "the only way to acquire a knowledge of scientific methods is in a laboratory, working with one's hands... while the only way to grasp the meaning of the humanities is to study men". $\mathrm{He}$ deplores the capture of precocious potential scholarship winners and their premature cramming "like geese". This has two harmful results. The first is the penalizing of the late developer. As he says : "The premium which we place on precociousness works directly against the processes which have made man what he is and may make him into Homo sapientior". The second is that general subjects are displaced from the boys' or girls' education, perhaps for ever. The effect of this, in his opinion, bears more heavily on science than on the humanities. Sir Gavin considers that one of the secrets of happiness in life is "the selection of the appropriate carrot to set before one's nose and that of other people". His particular carrot is "pothenology" ; and to illustrate what it really means he treats his readers to three of his own pothenological researches: Hannibal's route over the Alps, the origins of the Etruscans and the real cause of Gibbon's death. But does he really believe that Newton and Darwin would not have "won scholarships on our existing system" ? That is a most unpothenological statement to make.

\section{Institute of Seaweed Research}

SINCE the end of the War a new industry has been built up in Britain using more than forty thousand tons annually of a crop which, until recently, was looked upon as worthless. Whereas a few years ago there was only one very small alginate production unit in Scotland, there are now eight factories solely concerned with seaweed processing, which are served by an additional nine collecting and air-drying units. The current output of seaweed meal and alginates from these Scottish factories, together with the alginates and carragheenin produced in five further factories in England, has a sales value exceeding $£ 1$ million per annum. Britain's seaweed industry has now a larger output than that of any other country except Japan and the United States. This development has resulted from the combined efforts of scientists and industrialists, backed by the assistance freely given by government officials and by hundreds of interested individuals from all walks of life. A major contributory factor was the setting up in 1944 of the Scottish Seaweed Research Association "to determine whether the possibility existed of creating a stable Scottish seaweed industry which could compete with those of other countries and at the same time provide a considerable part-time crofter industry in the Highlands and Islands". The work of the Association during 1945-55, which was renamed the Institute of Seaweed Research in 1951, is described in a report which may be obtained from its Secretary at Inveresk, Midlothian, Scotland.

\section{Tobacco and Smoking}

IN a well-documented article in Health Education (14, No. 3; September 1956), Dr. Horace Joules shows that in $1955,11,900,000$ men aged sixteen and more were smoking an average of $15 \cdot 3$ cigarettes a day in Great Britain; the average consumption of $6,300,000$ women smokers was $8 \cdot 1$ daily. Of these, 65 per cent of men and 40 per cent of women more than sixteen are regular smokers; 87.3 per cent of male doctors more than thirty-five years old have similar habits. 'The present yearly death-rate from cancer of the bronchus of 17,000 in England and Wales is shown to be associated mainly with smoking, especially cigarettes. This disease has caused 100,000 deaths in the past ten years, and reasons are given for suggesting that this is only the early stages of an epidemic which will result in half a million deaths in the next twenty to thirty years. Preventive action by the medical profession and the Ministry of Health, it is thought, might be rapidly helpful. The mortality and morbidity from bronchitis are greater in Britain than in any other country where statistics are available. The part played by smoking in these conditions is important. The question is posed: Are there advantages from smoking which compensate for the known ill-effects on health ? The answer, according to Dr. Joules, must bo an emphatic no.

Isotopes Commercially available in North America

"The Isotope Index" published by the Scientific Equipment Corporation, Indianapolis 19, Indiana (U.S.A. and Canada, 2 dollars ; elsewhere, 2.50 dollars), is the first up-to-date (April 1, 1956) complete guide to the isotopes and isotope-labelled compounds available commercially and produced or sold by American or Canadian suppliers. Some two thousand items are listed from more than forty different suppliers. In general, the information given has been taken from the suppliers' catalogues or price sheets. Radioactive isotopes and labelled compounds of carbon-14, iodine-131, phosphorus-32 and sulphur-35 are dealt with in the first section, with the isotopes arranged in alphabetical order by name of element and then by atomic weight. 'The half-life, principal radiation, the forms in which the isotope is available and the cost are quoted, together with a reforence to the supplier. In the next section stable isotopes and the labelled compounds of carbon-13, hydrogen-2 and nitrogen-15 are listed, followed by information on available radioactive calibration standards, radiographic and therapeutic sourcos, and a complete list, with names and addresses, of the suppliers referred to in earlier sections. Finally, a brief section describes the recently revised licence requirements of the Atomic Energy Commission in the United States.

\section{Endocrinology of Invertebrates}

IN July 1955, immediately before the International Congress of Anatomy, an informal symposium on the endocrinology of invertebrates was held in Paris. This highly successful meeting was organized by Dr. I. Arvy and Dr. M. Gabe, of the Sorbonne, and by Dr. B. Scharrer, of the Albert Finstein College of Medicine in New York, and was attended by some three dozen workers in this field. The communications have now been published (Ann. Sci. Nat., Zool., 18 (fasc. 2), 125-337); and they form a most useful cross-section of the recent developments in this subject. The Swedish workers Óstlund and Fänge (Lund) describe the isolation in a highly purified state of a chromatophorotropic principle from the eyestalk of the shrimp Pandalus. The $Y$ organ of Crustacea discovered by Gabe has been shown by Echalier, another French worker, to control the moulting of decapod crustaceans. Karlson (Tübingen) describes the extraction from the silkworm of the moulting hormone 'ecdyson'. This has now been obtained in crystalline form and proves to be a non-nitrogenous substance with a molecular weight of about 300 . Another important contribution is that of CharniauxCotton (Paris), who has obtained clear evidence that an androgenic gland, quite separate from the gonad, 